\title{
Significado da atuação da equipe da Estratégia de Saúde da Família em uma comunidade socialmente vulnerável
}

\author{
The meaning of the performance of the Family Health Strategy team \\ in a socially vulnerable community
}

Dirce Stein Backes ${ }^{1}$

Marli Terezinha Stein Backes ${ }^{2}$

Alacoque Lorenzini Erdmann ${ }^{3}$

Andreas Büscher ${ }^{4}$

Mara Teixeira Marchiori ${ }^{1}$

Magda Santos Koerich ${ }^{5}$

${ }^{1}$ Curso de Enfermagem, Centro Universitário Franciscano. Rua dos Andradas 1614, Centro. 97010-032 Santa Maria

RS. backesdirce@ig.com.br

${ }^{2}$ Hospital-Escola

Universidade Federal de

Pelotas.

${ }^{3}$ Programa de Pós-

Graduação em Enfermagem,

Departamento de

Enfermagem, Centro de

Ciências da Saúde,

Universidade Federal de

Santa Catariana.

${ }^{4}$ Institute of Nursing

Science, University of

Bielefeld -Germany.

${ }^{5}$ Departamento de

Patologia, Centro de

Ciências da Saúde,

Universidade Federal de

Santa Catarina.
Abstract This study sought to understand the meaning of the performance of a Family Health Strategy team in a socially vulnerable community. Grounded Data Theory was used as a methodological benchmark and the data collection technique consisted of interviews with twenty-five Family Health Strategy professionals between July and December of 2009. Data analysis revealed that the Family Health Strategy can be seen as a facilitator and stimulator of the process of expansion and consolidation of healthcare networks. They represent a new approach in community intervention, by viewing the human being as a multidimensional and singular being, inserted in his/ her real context. A new assistential model is essentially being developed by the reorganization of healthcare practices, assisted by the multiplicity of complex relationships, interactions and associations that occur within the social and family context.

Key words The nurse's role, Community health nursing, Unified Health System, Family Health Program
Resumo O presente estudo objetivou compreender o significado da atuação profissional de uma equipe ESF em uma comunidade socialmente vulnerável. Utilizou-se como referencial metodológico a Teoria Fundamentada nos Dados e como técnica de coleta de dados a entrevista, realizada entre julho a dezembro de 2009, com 25 profissionais que integram a Estratégia Saúde da Família (ESF). A análise dos dados demonstrou que a ESF pode ser considerada uma estratégia facilitadora e estimuladora do processo de ampliação e de consolidação das redes de cuidado em saúde, à medida que sinaliza para uma nova abordagem de intervenção comunitária, pela valorização do ser humano como um ser singular e multidimensional, inserido em seu contexto real. Um novo modelo assistencial se desenvolve, em suma, mediante a reorganização da prática de atenção à saúde, intermediada pela multiplicidade de relações, interações e associações complexas que ocorrem no contexto familiar e social.

Palavras-chave Papel do enfermeiro, Enfermagem em saúde comunitária, Sistema Único de Saúde, Programa Saúde da Família 


\section{Introdução}

Com o movimento da Reforma Sanitária Brasileira, o conceito de saúde passou a ganhar novos significados e uma concepção mais abrangente dos determinantes que envolvem o processo saúde-doença. A saúde passa a ser apreendida como um bem público e de cidadania, garantida por direito a todo e qualquer cidadão brasileiro, independente de raça, cor e/ou condição econômica e social ${ }^{1}$.

A partir deste movimento foi criado o Sistema Único de Saúde (SUS), motivado pelas lutas participativas e as manifestações de um conjunto de necessidades sociais, que imprime um caráter ético-moral e defende a saúde como direito de todo cidadão brasileiro. Desenvolve-se, para tanto, com base em princípios de acesso, tais como a universalidade, a equidade e a integralidade e, ainda, em diretrizes organizativas como a descentralização, a regionalização, a hierarquização e a participação da comunidade ${ }^{2,3}$.

Como estratégia de reformulação do modelo brasileiro de atenção à saúde e o fortalecimento dos princípios e diretrizes do SUS, o Ministério da Saúde criou, em 1994, a Estratégia Saúde da Família (ESF), inicialmente denominada Programa de Saúde da Família ${ }^{4}$. A estratégia nasceu na tentativa de repensar os padrões de pensamento e comportamento dos profissionais e cidadãos brasileiros. Sistematizada e orientada por equipes de saúde da família que envolvem médicos, enfermeiros, técnicos de enfermagem, odontólogos e Agentes Comunitários de Saúde (ACS), a ESF buscou discutir e ampliar o tradicional modelo sanitário médico-curativista, a partir de uma abordagem coletiva, multi e interprofissional, centrada na família e na comunidade ${ }^{5-7}$.

Constata-se, no entanto, que as políticas sociais e de saúde, dentre elas a ESF, têm contribuído pouco para amenizar as condições de acesso e vulnerabilidade, mesmo tendo como unidade de atendimento a família em seu habitat e prever ações que levem em conta a possibilidade de detectar, no domicílio, as necessidades de suporte e, dessa forma, ampliar as redes de apoio social ${ }^{8,9}$. Com base nestas e em outras evidências e na tentativa de ampliar as discussões acerca da temática, questiona-se: Qual o significado da atuação profissional de uma equipe ESF em uma comunidade socialmente vulnerável?

O termo vulnerabilidade social ${ }^{10}$ está associado, neste contexto, a uma zona formada por famílias em condições sociais, econômicas e ambientais precárias, tais como o acesso à informa- ção, à educação, à assistência social e à saúde, à garantia de respeito aos direitos humanos e à situação sociopolítica e cultural.

Com base no exposto e tendo como referencial teórico o pensamento sistêmico, que possibilita negociar a conjunção complexa do uno ao múltiplo, ou do olhar as partes para apreender o todo e o todo para apreender as partes, o presente estudo teve por objetivo compreender o significado da atuação profissional de uma equipe ESF em uma comunidade socialmente vulnerável.

\section{Metodologia}

Dentre as várias metodologias qualitativas, a opção para este estudo foi a Teoria Fundamentada nos Dados (TFD) ou também chamada Grounded Theory, com o propósito de compreender o significado dos fenômenos a partir dos dados e da ação cotidiana.

Trata-se de uma metodologia originalmente desenvolvida por Glaser e Strauss, sociólogos americanos, que intentaram construir uma teoria assentada nos dados, com base na exploração do fenômeno na realidade em que o mesmo se insere, sendo que a construção teórica explica a ação no contexto social ${ }^{11}$.

O estudo foi realizado em uma comunidade composta por aproximadamente 26 mil habitantes, cujas famílias se encontram em situação social, econômica e ambiental precária. Na sua grande maioria, as famílias são compostas por seis ou mais integrantes e sobrevivem com uma renda igual ou inferior a um salário mínimo. Percebe-se, de forma crescente, o tráfico e o consumo de drogas ilícitas, principalmente, entre os adolescentes. A comunidade possui equipes de ESF atuando de forma ativa, mesmo que em número inferior ao desejado e necessário para atender à complexidade dos problemas sociais e de saúde.

Para a coleta de dados foram realizadas entrevistas com 25 profissionais que integram diferentes equipes de ESF, no sentido de comparar dados e ampliar as discussões acerca da temática. Dentre os participantes encontram-se: enfermeiros, médicos, odontólogos, técnicos de enfermagem e agentes de saúde, os quais foram selecionados com base na escala de trabalho, disponibilidade para a realização da entrevista em dias e horários previamente agendados e mediante a assinatura a do Termo de Consentimento Livre e Esclarecido. As entrevistas foram conduzidas com base em questões norteadoras, quais 
sejam: O que significa para você atuar em uma equipe ESF, mais especificamente em uma comunidade vulnerável? Como você percebe o seu trabalho neste espaço de inserção social?

A coleta e a análise de dados, processadas de forma sistemática e comparativa ${ }^{11}$, foram realizadas entre os meses de julho e dezembro de 2009. O método da TFD, por meio da análise comparativa, possibilitou construir hipóteses testáveis e gerar construtos teóricos que conduziram a delimitação da categoria central "ESF: estratégia facilitadora e estimuladora do processo de ampliação e consolidação das redes de cuidado em saúde".

Os aspectos éticos em relação à pesquisa com seres humanos foram observados, levando-se em conta as recomendações da Resolução CNS no 196/96, que prescreve a ética em pesquisa com seres humanos no Brasil ${ }^{12}$. O projeto foi aprovado pelo Comitê de Ética em Pesquisa do Centro Universitário Franciscano (UNIFRA). Para manter o anonimato das informações, os participantes do estudo foram identificados ao longo do texto pela letra "E" (entrevistado), seguida de um número correspondente à ordem de realização das entrevistas (E1, E2, E3... E25).

\section{Resultados}

A atuação profissional em uma equipe ESF está relacionada à compreensão do contexto social e singular de cada usuário e família. Os entrevistados evidenciaram, de modo geral, que as famílias são receptivas e acolhedoras à atuação da equipe e que a ESF representa uma estratégia facilitadora e estimuladora do processo de ampliação e consolidação das redes de cuidado em saúde. Ao utilizar a TFD como método de estudo, o significado da atuação de uma equipe ESF resultou em uma construção teórica ampla, com destaque para três subcategorias, cuja discussão desperta vários e diferentes sentimentos nos profissionais, tais como o reconhecimento e a valorização profissional; a ampliação dos processos interativos, como a formação do vínculo entre profissionalusuário e o surgimento de novas abordagens de cuidado em saúde.

\section{Reconhecimento e valorização profissional}

Com a inserção mais ativa e efetiva na realidade das famílias, os profissionais percebem que a sua prática transforma e é transformada a partir de sua entrada em uma realidade aparentemente complexa, para a qual não foram prepa- rados e os coloca em uma situação ao mesmo tempo desafiadora e instigadora. Mesmo tendo que desafiar as próprias possibilidades, a sensação de "completude e satisfação profissional", provocada pelo contato direto com o indivíduo em seu contexto familiar e comunitário é muito mais instigadora do que atuar no hospital, onde a aparente segurança tecnológica e o conforto da estrutura limitam a autonomia profissional, conforme evidencia a fala de um enfermeiro:

Atuar na família é muito mais instigador e animador. Lá eu preciso colocar todo o meu potencial para conseguir compreender, interagir... mas a minha satisfação agora é maior. No hospital tem muito aquela limitação profissional... No hospital eu não conseguia ir a fundo. $\mathrm{Na}$ atuação com as famílias, a gente precisa ir a fundo, se envolve com o todo. Na atuação com as famílias a gente tem um impacto direto... cria um vínculo maior. Hoje me sinto uma profissional completa (E2).

Assim como os enfermeiros, também os agentes comunitários demonstraram forte emoção, realização e valorização do seu trabalho ao relatarem fatos significativos de sua interação e vínculo com as famílias. Percebem que as famílias acolhem, valorizam e reconhecem, apesar de sua humildade e simplicidade, o envolvimento e o comprometimento profissional. O significado desta atuação pode ser confirmado na fala:

Emociono-me muito com este trabalho. Eu morava no centro, mas me mudei para cá para trabalhar com estas famílias. Fiquei muito sensibilizado, quando em uma família o senhor disse que não poderia me convidar para entrar na casa porque não tinha cadeira para me oferecer. Senti que ele estava valorizando o meu trabalho, mas não tinha o que oferecer em troca (E5).

\section{Ampliação dos processos interativos}

A inserção no seio da família amplia, no entender dos entrevistados, as interações intersubjetivas, fortalece os vínculos de confiança entre profissionais e usuários e possibilita a satisfação tanto do profissional quanto do usuário: Tenho um retorno que é positivo. E parece que este alimenta e motiva a volta à família, à comunidade! Sabia que ali poderia interagir mais e melhor (E8). A inserção na família e na comunidade possibilita, de acordo com os profissionais, um aprendizado contínuo pela intensa troca de experiências. Trata-se de um espaço que fortalece a autonomia do profissional e do usuário/família, além de estimular o protagonismo e a emancipação social, conforme os depoimentos: Eu preciso en- 
contrar espaços onde eu possa fortalecer a autonomia... o contato com a família me proporciona isto... (E9). Na família a gente precisa levar em conta a autonomia do usuário... tem a possibilidade de troca, de eu também aprender e crescer. Então existe toda uma interação, ele passa a ser autor $e$ ator do processo (E13).

O espaço da família é apreendido como um local sensível e propício à ampliação das interações profissional-família-comunidade, como menciona um dos entrevistados: Eu acredito que o espaço da família é um espaço onde podemos fortalecer a nossa prática profissional, na perspectiva do cuidado sensivel (E11).

A atuação em uma equipe saúde da família, na visão dos profissionais, está relacionada ao envolvimento, à responsabilidade e à resolutividade das ações de saúde. Como consequência desse processo, os profissionais percebem, além da satisfação do usuário/família, a conquista de uma maior credibilidade e participação social.

Para os entrevistados, o profissional de saúde precisa ser criativo e saber aproveitar os recursos que a família já possui. No caso do cuidado em saúde, é preciso valorizar o conhecimento que o usuário possui e o significado que atribui ao processo de viver saudável. É preciso aproveitar os recursos disponíveis e descobrir alternativas na realidade em que a família está inserida. A dificuldade, no entender dos entrevistados, está no fato de que tudo se move pelo mais fácil e a doença ainda prevalece como a comunicação socialmente relevante. [...] é mais fácil você ir com uma receita pronta para tal doença (E15). Por outro lado, os profissionais mostram que a ciência evoluiu de tal modo que acabou deixando de lado as práticas alternativas que fazem parte da vida da família. A postura das profissionais tem que ser menos sofisticada. O segredo muitas vezes está nas mãos dos usuários, mas é preciso dialogar (E18).

\section{O despertar de novas abordagens de cuidado em saúde}

Os profissionais se encontram diante de um novo modelo assistencial no qual o impacto do desconhecido, do incerto e do inesperado são inevitáveis, mesmo que altamente instigadores. Essa nova abordagem de cuidado em saúde, no entanto, não é percebida e sentida somente pelos profissionais, mas também pelos usuários, para os quais o cuidado com foco na família acaba sendo, à primeira vista, desafiador e desestabilizador. O usuário de saúde, conforme reflete a fala a seguir, ainda está fortemente impregnado por um modelo de assistência fragmentado, dicotômico e pouco resolutivo. O usuário ainda está muito acostumado a ser tratado em partes, então no início ele estranha muito... eu percebo nas primeiras visitas, que o usuário e a família estão desacreditados e desmotivados (E7). Nessa direção, os profissionais demonstram que a atuação em uma equipe ESF se constitui num processo de transformação gradual, que implica em mudanças culturais e de modelos de referência. Reconhecem que a equipe de ESF tem grande poder de transformação no âmbito das famílias e comunidades, pela possibilidade de intervir direta e amplamente na complexidade dos problemas.

Ainda que a transformação possa ser promovida em qualquer local, o espaço da família se apresenta com maior possibilidades, pela capacidade de potencializar as relações, as interações e as associações, articuladas por meio do cuidado em rede, conforme reflete a fala a seguir:

Quando você vai fazer a visita na família, por exemplo, e você consegue orientar uma pessoa e esta pessoa muda o seu comportamento, você já provocou uma transformação. É pequena, mas você já mudou, porque esta pessoa fala para o vizinho, fala para o amigo, fala para o filho e já cria uma rede de cuidados. São as relações sociais que podem ter um grande impacto sobre a saúde como um todo (E20).

Os resultados evidenciam que apesar de ser uma prática complexa e desafiadora, os profissionais da ESF buscam delinear o cuidado em saúde de forma integrada e planejada: Todas as ações desenvolvidas pela equipe têm um planejamento prévio e são discutidas por toda a equipe, respeitando-se a autonomia de cada profissional (E22). Os profissionais entendem que o planejamento conjunto e integrado das ações de saúde, assegura a qualidade, a integralidade, a continuidade e a resolutividade da rede de cuidados em saúde. Nessa direção, os entrevistados consideram que a atuação da equipe ESF se constitui numa importante estratégia para a efetiva transformação do modelo de saúde: A ESF é uma ferramenta que, aliada a outras, poderá resultar em pouco tempo numa mudança efetiva do modelo de saúde (E24).

\section{Discussão}

Orientados por uma abordagem assistencial mais aberta e flexível, os entrevistados evidenciaram a dialogicidade que existe e que deve existir entre os diferentes atores envolvidos na equipe ESF. Essa 
dialogicidade pode ser evidenciada à medida que os profissionais e as famílias estabelecem trocas recíprocas, pela capacidade de uns e outros acolherem e compreenderem as reais necessidades.

É imprescindível que os profissionais se posicionem de forma positiva mediante a multiplicidade de determinantes sociais envolvidos no processo saúde doença e que se mostram de maneira muito mais explícita no contexto familiar do que no limitado espaço do consultório e/ou hospital. A comunidade analisada se destaca pelas condições adversas e complexas de adoecimento, pobreza e exclusão que são comuns em várias comunidades brasileiras e que exigem dos profissionais de ESF muita criatividade e estratégias para transcender o modelo medicalizante, que é exigido pelos usuários e persiste nas práticas profissionais da saúde coletiva e ESF ${ }^{13}$.

A atuação na família se apresenta como um espaço aberto para a discussão e o compartilhamento de saberes e vivências significativas, mesmo que motivadas por situações complexas, aparentemente confusas e sem respostas. No entanto, é nas situações complexas, aparentemente confusas e difíceis de serem compreendidas, que se escondem as maiores possibilidades criativas e interativas, visto que estas exigem maior reflexão e a busca constante da verdade, que se mostra de forma cada vez mais complexa ${ }^{14,15}$.

Nesse campo de discussões, é preciso considerar que o conhecimento precisa ser dialogado, compartilhado e confrontado. Esta ideia fica evidente à medida que os profissionais e usuários/ famílias precisam negociar novos entendimentos que antes pareciam serem simples e fáceis de serem editados. Ou seja, à medida que precisam negociar a conjunção complexa do uno ao múltiplo, ou do olhar as partes para compreender o todo e o todo para compreender as partes que integram os diferentes eventos circulares da dinâmica familiar e social ${ }^{16}$. Apenas há alguns anos o especialista da saúde com um mínimo de apoio pessoal e tecnológico e com o conhecimento e competências que aprendera nos bancos escolares, deliberava e resolvia a maior parte dos problemas relacionados à saúde. Hoje, esse processo precisa ser ampliado, confrontado e integrado à rede de cuidados, visto que nas diferentes realidades familiares, em todos os níveis e na sociedade em geral, o cuidado em saúde requer respostas cada vez mais complexas ${ }^{17}$.

A compreensão da necessidade de atuar em equipe e de forma complementar, bem como da necessidade de um olhar aberto e sensível à realidade do outro, torna evidente que os profissio- nais precisam atuar cada vez mais de forma integrada e articulada em redes.

O vínculo, a participação da comunidade, o trabalho em equipe e as novas práticas de educação em saúde, além da mudança do comportamento assistencialista de profissionais e usuários, são objetivos destacados nos dados e que se colocam como um norte para a ESF.

Para alcançar novas abordagens de cuidado em saúde é preciso, portanto, estar conectado em equipe e ter a iniciativa de olhar o todo e não somente as partes, isto é, o seu fragmento. É preciso, para tanto, que os profissionais se desloquem do tradicional conceito de saúde, a fim de ampliar o seu campo de visão sistêmica. Sob esse olhar, fica evidente a necessidade de adentrar novos referenciais capazes de ampliar a intervenção familiar, pela ampliação das possibilidades interativas, de modo a permitir a auto-organização dos diferentes atores sociais ${ }^{18}$.

$\mathrm{Na}$ busca pela aproximação da ESF com o campo de visão sistêmico, é preciso compreender que o objetivo do conhecimento e/ou da intervenção no habitat da família, não é descobrir o segredo ou a equação chave para a mudança do modo assistencial, mas dialogar com o conhecimento dos diferentes atores sociais e construir, a partir das pequenas e/ou grandes conquistas diárias dos indivíduos, mesmo que isto implique em negociar com a incerteza, as mudanças desejadas ${ }^{19,20}$. Significa, em suma, possibilitar ao usuário ser autor da sua história e considerar que "quanto mais perto à decisão fica do fato, mais a decisão a ser tomada é legítima e mais chances haverá de acerto" ${ }^{20}$

A portaria que instituiu a ESF como política nacional da Atenção Básica em 2006, destaca a necessidade da educação continuada com forte direcionamento para a formação de especialistas em $\mathrm{ESF}^{21}$. Para alcançar esse objetivo é preciso, no entanto, o apoio das esferas públicas, especialmente da gestão municipal e estadual, a fim de permitir aos profissionais a ampliação e ressignificação do cuidado em rede. Os dados sinalizam para a educação permanente, a remuneração e a alocação de recursos materiais e humanos como aspectos que apontam para o reconhecimento e a valorização profissional.

Para a ampliação dos processos interativos, se destaca o papel das Universidades e das Escolas Técnicas na formação de profissionais da saúde competentes do ponto de vista técnico, mas também com competência ética e humanística, no sentido de estabelecer vínculos duradouros entre os serviços de saúde e os usuários. Assim, 
será possível instituir e tornar rotineira a nova abordagem de cuidados em saúde, voltada para o usuário como protagonista da sua história.

A complexidade que envolve o setor saúde exige que as ações sejam desenvolvidas em várias frentes, com destaque para as parcerias e a integração com instituições e projetos sociais, tendo a universidade como parceira nas ações de promoção da saúde e na construção de espaços de cidadania, como previsto na Política de Atenção Básica e ESF.

Sendo assim, é possível argumentar que a ESF pode ser considerada uma estratégia facilitadora e estimuladora do processo de ampliação e consolidação das redes de cuidado em saúde, de modo especial nas comunidades socialmente vulneráveis, pela possibilidade de dialogar saberes, trocar ideias e fortalecer a autonomia dos atores sociais, sejam eles profissionais e/ou usuários.

\section{Considerações finais}

O significado da atuação profissional de uma equipe ESF em uma comunidade socialmente vulnerável está relacionado às possibilidades interativas e dialógicas, à possibilidade de fortalecer a autonomia dos diferentes atores envolvidos no processo de cuidado em saúde, à capacidade de romper com modelos tradicionais, à valorização das singularidades humanas e ao fortalecimento das redes interativas e associativas.
A ESF pode ser compreendida, nessa perspectiva, como uma nova ferramenta assistencial, ou seja, uma nova abordagem de intervenção em saúde, na qual e pela qual os profissionais têm a possibilidade de interagir proativamente na realidade das famílias e comunidades.

Com a inserção ativa e efetiva na realidade das famílias, os profissionais percebem que a sua prática transforma e é transformada, mesmo que para alguns a inserção em uma comunidade socialmente vulnerável seja desafiadora e instigadora. De modo geral, os profissionais reconhecem que a atuação na realidade concreta das famílias provoca sentimentos de satisfação e realização, pela valorização do indivíduo/família como um ser singular e protagonista da sua própria história. Dito de outro modo, pela possibilidade de promover o desenvolvimento social e a ampliação das oportunidades reais dos seres humanos pela participação ativa e participativa no processo saúde-doença.

A ESF como estratégia facilitadora e estimuladora do processo de ampliação e consolidação das redes de cuidado em saúde não se traduz em uma prática linear e pontual, mas se constitui num processo gradual, dinamizada pela integração de uma visão sistêmica e intermediada pela multiplicidade de relações e interações que interferem positivamente tanto na atuação dos profissionais de saúde, quanto na dinâmica dos usuários/famílias.

\section{Colaboradores}

DS Backes trabalhou na redação do artigo e interpretação dos dados; MTS Backes e AL Erdmann trabalharam na concepção, delineamento e interpretação dos dados; A Büscher trabalhou na concepção, análise e revisão crítica do artigo; MT Marchiori trabalhou na pesquisa e provação da versão a ser publicada; e, MS Koerich trabalhou na revisão do artigo e discussão dos dados. 


\section{Referências}

1. Fleury S. Reforma Sanitária Brasileira: dilemas entre o instituinte e o instituído. Cien Saude Colet 2009; 14(3):743-751.

2. Brasil. Ministério da Saúde. O desenvolvimento do Sistema Único de Saúde: avanços, desafios e reafirmação dos seus princípios e diretrizes. Brasília: Ministério da Saúde; 2002.

3. Menicucci TMG. O Sistema Único de Saúde, 20 anos: balanço e perspectivas. Cad Saude Publica 2009; 25(7):1620-1625.

4. Brasil. Ministério da Saúde. Política Nacional de Atenção Básica, estabelecendo a revisão de diretrizes e normas para a organização da Atenção Básica para o Programa Saúde da Família e Programa Agentes Comunitários de Saúde. Brasília: Ministério da Saúde; 2006.

5. Alves VS. Um modelo de educação em saúde para o Programa Saúde da Família: pela integralidade da atenção e reorientação do modelo assistencial. Interface Comunic Saúde Educ 2005; 9(16):39-52.

6. Neto FRG, Sampaio JJC. Gerentes do território na Estratégia Saúde da Família: análise e perfil de necessidades de qualificação. Rev Bras Enfermagem 2007; 60(6):687-695.

7. Giovanella L, Mendonça MHM, Almeida PF. Saúde da Família: limites e possibilidades para uma abordagem integral de atenção primária à saúde no Brasil. Cien Saude Colet 2009; 14(3):783-794.

8. Gomes MA, Pereira MLD. Família em situação de vulnerabilidade social: uma questão de políticas públicas. Cien Saude Colet 2005; 10(2):357-363.

9. Backes DS, Koerich MS, Rodrigues ACRL, Drago LC, Klock P, Erdmann AL. O que os usuários pensam e falam do Sistema Único de Saúde? Uma análise dos significados à luz da Carta dos Direitos dos Usuários. Cien Saude Colet 2009; 14 (3):903-910.

10. Prati LE, Couto MCP, Koller SH. Famílias em vulnerabilidade social: rastreamento de termos utilizados por terapeutas de família. Psic Teor e Pesq 2009; 25(3):231-239.

11. Strauss A, Corbin J. Bases de la investigación cualitativa. Técnicas y procedimientos para desarrollar la teoría fundamentada. Medelin: Universidad de Antioquia; 2002.
12. Brasil. Ministério da Saúde. Fundação Osvaldo Cruz. Programa de Saúde da Família: avaliação da implementação em dez grandes centros urbanos: síntese dos principais resultados. $2^{\text {a }}$ ed. Brasília: Ministério da Saúde; 2005.

13. Brasil. Conselho Nacional de Saúde. Diretrizes e normas regulamentadoras de pesquisa em seres humanos. Resolução no 196, de 10 de outubro de 1996: diretrizes e normas regulamentadoras de pesquisa envolvendo seres humanos. Brasília: Ministério da Saúde; 1996.

14. Falcón GCS, Erdmann AL, Backes DS. Meanings of care in health promotion. Rev Latino-Am. Enfer 2008; 16(3):419-424.

15. Morin E. A cabeça bem feita: repensar a reforma reformar o pensamento. $10^{\text {a }}$ ed. Rio de Janeiro: Bertrand Brasil; 2004.

16. Vasconcelos EM. Complexidade e pesquisa interdisciplinar: Epistemiologia e metodologia operatativa. $2^{\mathrm{a}}$ ed. Petrópolis (RJ): Vozes; 2002.

17. Plsek PE, Greenhalgh T. Complexity science. The challenge of complexity in health care. University College London: BMJ 2001; 19(2):625-638.

18. Backes DS. Viewing nursing care as a social enterprising practice [these]. Santa Catarina (SC): Universidade Federal de Santa Catarina; 2008.

19. Morin E. Ciência com consciência. $7^{\text {a }}$ ed. Rio de Janeiro: Bertrand Brasil; 2003.

20. Büscher A. Negotiating Helpful Action: A substantive Theory on the Relationship between Formal and Informal Care [theses]. Finland: University of Tampere; 2007.

21. Martins PH. Ação Pública, redes e arranjos familiares. In: Fontes B, Martins PH, organizadores. Redes, Práticas Associativas e Gestão Pública. Recife: Ed. Universitária da UFPE; 2006, p.19-50.

Artigo apresentado em 15/03/2011

Aprovado em 03/05/2011

Versão final apresentada em 24/06/2011 